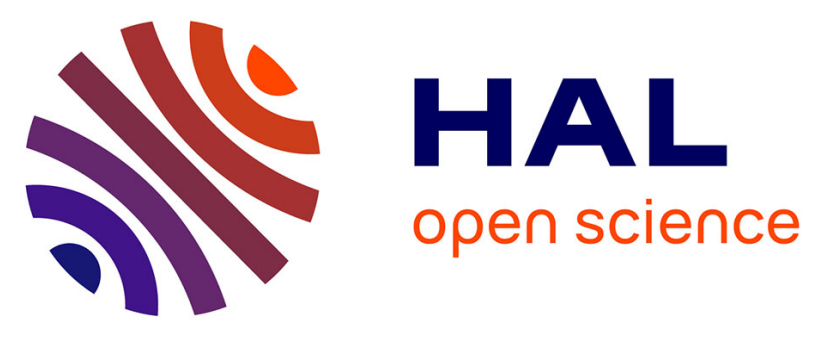

\title{
Interspecific Variability of Biomass Production of Young Coffea: No Influence of Branch Pruning. Experimental Evidence and Theoretical Analysis
}

Veronique Letort, Sylvie Sabatier, Sélastique Akaffou, Serge Hamon, Perla Hamon, P. de Reffye

\section{To cite this version:}

Veronique Letort, Sylvie Sabatier, Sélastique Akaffou, Serge Hamon, Perla Hamon, et al.. Interspecific Variability of Biomass Production of Young Coffea: No Influence of Branch Pruning. Experimental Evidence and Theoretical Analysis. 2012 IEEE 4th International Symposium on Plant Growth Modeling, Simulation, Visualization and Applications, Oct 2012, Shanghai, China. pp.224227, 10.1109/pma.2012.6524838. hal-00781194

HAL Id: hal-00781194

https://hal-centralesupelec.archives-ouvertes.fr/hal-00781194

Submitted on 25 Jan 2013

HAL is a multi-disciplinary open access archive for the deposit and dissemination of scientific research documents, whether they are published or not. The documents may come from teaching and research institutions in France or abroad, or from public or private research centers.
L'archive ouverte pluridisciplinaire HAL, est destinée au dépôt et à la diffusion de documents scientifiques de niveau recherche, publiés ou non, émanant des établissements d'enseignement et de recherche français ou étrangers, des laboratoires publics ou privés. 


\title{
Interspecific Variability of Biomass Production of Young Coffea: No Influence of Branch Pruning. Experimental Evidence and Theoretical Analysis
}

\author{
Véronique Letort ${ }^{*}$, Sylvie Sabatier ${ }^{\dagger}$, Selastique Akaffou ${ }^{\ddagger}$, Serge Hamon ${ }^{\S}$, Perla Hamon $\S$ and Philippe de Reffye ${ }^{\dagger}$ \\ *Ecole Centrale Paris, MAS, F-92295 France \& INRIA Saclay, F-91893 France, letort@mas.ecp.fr \\ ${ }^{\dagger}$ CIRAD, UMR AMAP, Montpellier, F-34000 France, sylvie-annabel.sabatier@cirad.fr,dereffye@cirad.fr \\ ${ }^{\ddagger}$ URES Daloa, B150, Daloa, Côte d'Ivoire, sakaffou@yahoo.fr \\ §IRD, UMR DIADE, BP 64201, Montpellier, F-34000 France, perla.hamon@ird.fr, serge.hamon@ird.fr
}

\begin{abstract}
Understanding the mechanisms of plant adaptation to their habitat can help developing relevant conservation politics, which is a crucial issue for several Coffea species. This comes through an understanding of the links between genetic diversity and architectural plasticity. In this study, we investigated the biomass production and allocation strategies of young Coffea trees for nine African species with different countries of origin, that were submitted to a pruning treatment. It revealed that despite large inter-specific differences, the pruning treatment had no influence on biomass production and allocation for these young trees. We propose a theoretical analysis of this result, based on classical modelling hypotheses.
\end{abstract}

Keywords-GreenLab; topology; biomass allocation

\section{INTRODUCTION}

African Coffea species have developed different strategies to adapt to their habitat, that range from humid evergreen forests to seasonally dry deciduous forests [1]. Understanding the relationship between genetic diversity and architectural plasticity is key for the development of adequate politics for species preservation of Coffea and of new guidelines to improve agronomic productions. Coffea species exhibit different allocation strategies according to their geographical distribution: in humid zones, plants tend to invest more biomass into the leaf compartment relatively to the stem compartment, and inversely in drier zones. In this study, we investigate the robustness of this allocation strategy to changes in plant architecture, namely branching patterns, for young Coffea trees of nine African species.

Coupling experimental analysis with a modelling approach can provide additional insights to help interpreting the results. In particular, it can help assessing the role of interactions between plant development and physiological functioning on plant plasticity. In some cases, the equations are analytically tractable and can be used to study to what extent topological development influences production and partitioning at whole plant level.

In this paper, we investigate the effects of architecture on the biomass production and allocation for nine Coffea species with contrasted habits (large leaves and small number of phytomers/ small leaves and high number of phytomers). For young Coffea trees, we compare control plants (branched plant) with plants that were submitted to lateral axis ablation treatment. We propose a theoretical analysis of this result and we finally discuss the consequences of some modelling assumptions.

\section{EXPERIMENTAL DESIGN AND RESUlts}

\section{A. Plant Material and Experimental Design}

Nine Coffea species were selected for their diversity of distribution areas (Table I) and for their diversity of architectural characters (Table II, Fig. 1). Two experiments were carried out at IRD tropical greenhouse (Montpellier, France) from 1 March to 8 December 2008 and from 1 May 2009 to 18 January 2010. All the plants were obtained from cuttings from mother plants maintained in IRD tropical greenhouses. Plants were grown in regularly spaced PVC pots $(30 \mathrm{~cm}$ between pots) during nine months. Plants were in a fog at several times per day and a daily rain during 30 minutes. Lateral branches were systematically removed after emergence to keep only the main stem. Plants subjected to this lateral axis ablation treatment ('plant without branch') were compared with plant without axis ablation ('control plant') to assess the impact of shoot structure on plant growth. Experiment 1 included a data set from growth monitoring for all species. Experiment 2 included a data set from only three selected species.

Table I

STUdiEd COFFEA SPECIES. ORIGIN AND HABITAT FROM [1].

\begin{tabular}{lcll}
\hline Species & Code & Origin & Habitat \\
\hline C. stenophylla & STE & Côte d'Ivoire & H/D (Slopes, ridges) \\
C. humilis & HUM & Côte d'Ivoire & H \\
C. liberica var liberica & LIB & West Africa & H \\
C. brevipes & BRE & Cameroon & H \\
C. canephora & CAN & Cameroon & H \\
C. liberica var dewevrei & DEW & Centr. Africa & H/D \\
C. racemosa & RAC & Tanzania & D (littoral forest) \\
C. pseudozanguebariae & PSE & Kenya & D (littoral forest) \\
C. arabica & ARA & Ethiopia & H \\
\hline
\end{tabular}

H: Humid evergreen forest, D: Seasonaly dry mixed evergreen-deciduous forest

Plants were described phytomer by phytomer (a segment of the shoot that includes an internode together 


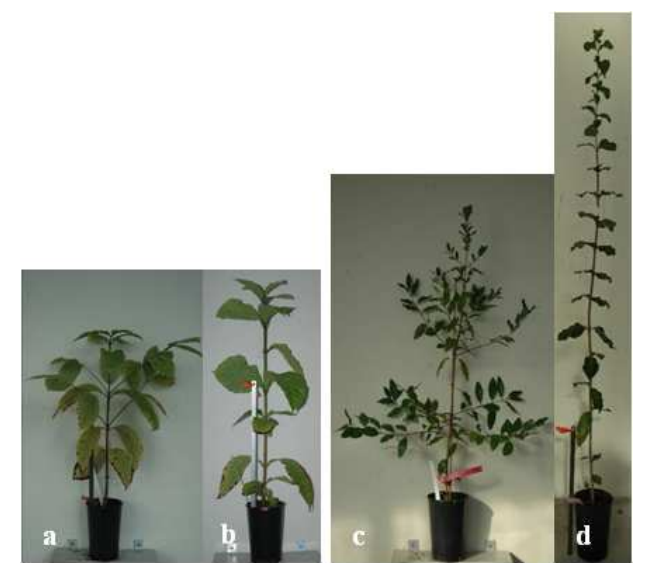

Figure 1. Habit of Coffea canephora (CAN): (a) control plant, (b) plant without branch; and Coffea racemosa (RAC): (c) control plant; (d) plant without branch. Photographies December 2008.

with the leaf and axillary production). Plant topology was recorded following MTG formalism [2] using Xplo software (http://amapstudio.cirad.fr/). For each phytomer, the length of the underlying internode, the presence of branches and leaves were recorded. Each leaf was cut, weighed and scanned. Leaf areas were estimated by analyzing the images with Taoster (plug-in implemented in ImageJ freeware [3]). The plant axes were cut internode by internode. The fresh mass of each phytomer (stem and leaves have been separated) was recorded.

\section{B. Investigation on Experimental Data}

Results illustrate the high variability of plant height and number of internodes of main stem among the studied species (Table II). This is also illustrated in Fig. 1 that shows the contrasted habit of $C$. canephora and $C$. racemosa. Generally, the height of plants without branch were higher than those of control plants (Table II). It can also be noted that Coffea racemosa (RAC) has a large height and number of phytomers compared with other species.

Despite this inter-species variability, a common trend can be observed for all the species: branched plants (control plants) and plants without branch have similar aerial mass (Fig. 2A). The difference was tested with a two-sided two samples Welch T-test and found significant only for $C$. racemos $a$ at the level $\mathrm{p}<0.05$ (but not at the level $\mathrm{p}<0.01$ ). A more detailed investigation at compartment level shows that this is corroborated by similar patterns of compartment mass ratios within the plants: as shown in Fig. 2B-C, the control plants and plants without branch have similar stem mass and leaf mass respectively (no significant differences were found at the level $\mathrm{p}<0.1$ for stem and blade compartment mass for the three species). Biomass allocation nevertheless varies from one species to another one: for instance, contrary to the two other species, the partitioning of biomass between
Table II

CHARACTERISTICS OF MEASURED INDIVIDUALS PER SPECIES FOR CONTROL PLANTS (C) AND PLANT WITHOUT BRANCH (P: PRUNED)

\begin{tabular}{|c|c|c|c|c|c|c|}
\hline \multirow[t]{2}{*}{ Spec. } & \multicolumn{2}{|c|}{$\mathrm{N}$} & \multicolumn{2}{|c|}{ Height $(\mathrm{cm})$} & \multicolumn{2}{|c|}{ Nb. phyt } \\
\hline & $\mathrm{C}$ & $\bar{P}$ & $\mathrm{C}$ & $\mathrm{P}$ & $\mathrm{C}$ & $\mathrm{P}$ \\
\hline \multicolumn{7}{|c|}{2008 Experiment } \\
\hline HUM & 4 & 8 & $12.52(4.10)$ & $17.77_{(8.12)}$ & $9.25(2.63)$ & $8.87_{(2.29)}$ \\
\hline STE & 4 & 7 & 27.52 (15.66) & $32.79_{(3.80)}$ & $11.25(3.40)$ & $13.14_{(1.34)}$ \\
\hline LIB & 3 & 9 & 27.40 (10.30) & 41.82 (14.94) & 10.00 & $10.44(2.35)$ \\
\hline CAN & 4 & 7 & $39.52(7.45)$ & 46.91 (13.05) & $8.00(0)$ & $10.57(0.97)$ \\
\hline BRE & 3 & 7 & $17.73(2.34)$ & $27.84(7.51)$ & $9.33(1.53)$ & $10.71(1.70)$ \\
\hline DEW & 1 & 4 & 60.40 & 49.12 (11.91) & 10.00 & $8.00(0.81)$ \\
\hline ARA & 3 & 9 & $44.80(0.96)$ & 60.69 (16.40) & $10.00(1)$ & $14.00_{(2.87)}$ \\
\hline PSE & 4 & 8 & 59.85 (24.99) & $85.32(20.51)$ & $12.50(4.12)$ & $17.00_{(2.14)}$ \\
\hline RAC & 4 & 7 & 63.09 (26.34) & $99.41(6.05)$ & $19.5(4.65)$ & $26.43(1.51)$ \\
\hline \multicolumn{7}{|c|}{2009 Experiment } \\
\hline HUM & 6 & 5 & $6.93(2.77)$ & $7.22(2.00)$ & $7.83(1.72)$ & $8.60(1.95)$ \\
\hline CAN & 6 & 6 & 38.43 (10.91) & $34.80_{(8.46)}$ & 8.33 & $9.33(1.63)$ \\
\hline RAC & 6 & 6 & $48.00(7.36)$ & 77.93 (19.95) & $16.83(2.64)$ & $21.50(4.08)$ \\
\hline
\end{tabular}

$\mathrm{N}$ : number of individuals; Height: mean (standard deviation) height; $\mathrm{Nb}$. Phyt: mean (standard deviation) number of phytomers of the main stem (PA1).
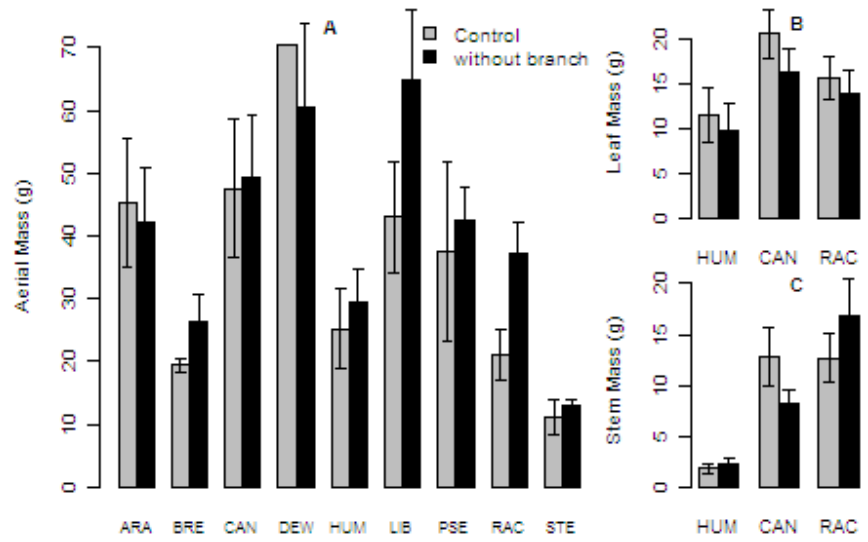

Figure 2. A: Mean (standard deviation) aerial mass according to plant treatment for each species and for 2008 experiment. B,C: Mean (standard deviation) leaf and stem mass $(\mathrm{g})$ according to plant treatment for three species (HUM, CAN, RAC) and for 2009 experiment.

stem and leaf of $C$. racemosa favours the stem.

\section{Theoretical AnALysis}

The experimental results presented in the previous section suggest that the pruning treatment does not affect the allocation strategy nor the biomass production of these young Coffea trees. In this section, we show that this result can be theoretically reproduced when considering the plant as a mere source-sink system with proportional allocation.

Let us consider that the plant topological development is fixed. Topology is defined as the graph of relative connexions (e.g. apical or lateral) between the set of basic units used for the description of the plant structure, here phytomers. Young Coffea trees follow the Roux architectural model, characterized by monopodial orthotropic trunk meristem which shows continuous growth and plagiotropic branches. 
The description of the topological development relies on two classes of axes, that are indexed by a parameter called physiological age (PA) [4]: PA is 1 for the trunk and 2 for branches. This phytomer organization can be written using different formalisms - e.g. automata [5], formal grammars, L-Systems [6] - and can be driven by any kind of deterministic or stochastic rules.

We note $t$ the time step $(t \in \mathbb{N}$ ), called growth cycle, equal to the minimal duration between the emission of two successive phytomers, expressed in thermal time. The plant physiology is represented as a proportional sourcesink system at organ scale. The biomass production at each growth cycle, $Q(t)$, is shared between all the growing organs of the plant, regardless of their position and proportionally to their demand. The increment of biomass $q_{k}^{o}(i, t)$ acquired by an organ of type $o$ ( $o=a$ : blades, $o=i$ : internodes $)$, age $i$ and PA $k$ at growth cycle $t$ is:

$$
q_{k}^{o}(i, t)=P_{k}^{o} \phi^{o}(i) \frac{Q(t)}{D(t)}
$$

with $D(t)$ the total plant demand and where organ demand is written as the product of a sink strength $P_{k}^{o}$ and a sink variation function $i \mapsto \phi^{o}(i)$, defined on $\mathbb{R} \rightarrow[0,1]$, that can take for instance the form of a normalized Beta density law [7] whose support is included in $\left[0, t_{x}\right], t_{x}$ being expansion duration.

In that context, the plant total blade area, $S(t)$, can be expressed as a function of the cumulated biomass attributed throughout their expansion to leaves that are still active, i.e. with a chronological age less than the activity duration $t_{a}$ $\left(t_{a} \in \mathbb{N}^{*}\right)$ :

$S(t)=\frac{1}{e} \sum_{i=1}^{\min \left(t, t_{a}\right)} \sum_{k=1}^{P_{m}} N_{k}^{a}(t-i+1) P_{k}^{a} \sum_{j=1}^{i} \frac{\phi^{a}(j) Q(t-i+j-1)}{D(t-i+j-1)}$

where $e$ denotes specific blade mass $\left(\mathrm{g} . \mathrm{cm}^{-2}\right), N_{k}^{a}(t)$ is the number of leaves of PA $k$ appearing at cycle $t$, and $P_{m}=2$ is the maximal physiological age. This expression shows that the plant production depends on its development through the demand (that includes numbers of organs appearing at each growth cycle) and the numbers of blades.

In the case of young Coffea trees, let us assume that the following conditions are met:

- leaf senescence is negligible (leaves were still active when harvested for measurements): $t \leq t_{a}$

- biomass allocation to secondary growth (rings) is negligible

- sink coefficients for PA 2 branches are proportional to those of PA 1:

$\forall o \in\{a, i\}, \forall k \in\{1,2\}, P_{k}^{o}=c_{k} \cdot P_{1}^{o}$ with $c_{1}=1$

- sink variation functions have similar shapes for blades and internodes: $\phi^{i}=\phi^{a}$

- the plant biomass production can be defined as a function $f$ of the total blade area of the plant, $S(t)$,

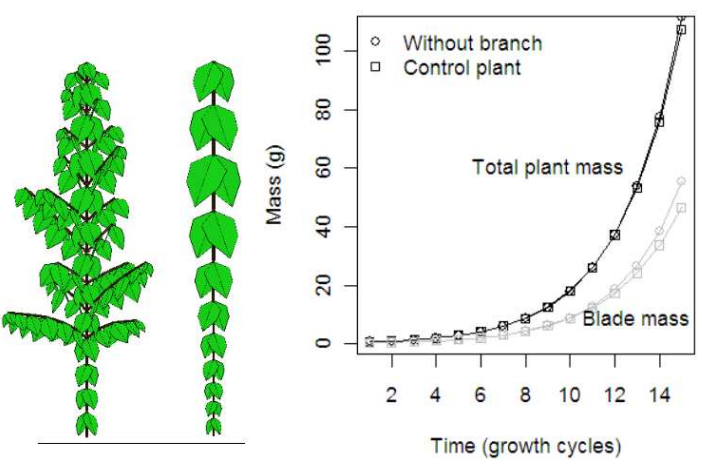

Figure 3. Simulated young Coffea trees with stochastic topology (Rhythm ratio: 0.8 , growth probability for PA 1: 0.8 , and for PA 2 branches: 0.4 ) and arbitrary chosen, but realistic, functional parameters, having similar biomass production profiles and partitioning dynamics; Gloups software [de Reffye P., CIRAD] with 3D output using Ligdraw Software.

and of some set of environmental factors, $E(t)$ :

$$
Q(t)=f(S(t), E(t), P)
$$

with $P$ a set of possible parameters.

Under these hypotheses, the expression of the demand is:

$D(t-1)=\sum_{j=1}^{\min \left(t, t_{x}\right)} \sum_{k=1}^{2} c_{k} N_{k}^{a}(t-j+1) \phi^{a}(j)\left[\frac{1}{2} P_{1}^{i}+P_{1}^{a}\right]$

Note that the demand is calculated at end of growth cycles so $D(t-1)$ account for the new organs appearing at growth cycle $t$. By replacing this term in (2) and after several rearrangements, we get for all $t>0$ :

$$
S(t)=\frac{1}{e} \sum_{p=1}^{\min \left(t, t_{a}\right)} P_{1}^{a} \frac{Q_{t-p} \sum_{j=1}^{\min \left(t_{a}-p+1, t-p+1, t_{x}\right)} \phi^{a}(j) \cdot c N(t-p-j+2)}{\left(\frac{1}{2} P_{1}^{i}+P_{1}^{a}\right) \sum_{i=1}^{\min \left(t-p+1, t_{x}\right)} \phi^{a}(i) c N(t-p-i+2)}
$$

where $c N(t)=c_{1} N_{1}(t)+c_{2} N_{2}(t)$. One can see that for $t_{a}>t$, the ratio simplifies and after transferring in (3), we get the resulting recurrent equation of biomass dynamics as:

$$
Q(t)=f\left(\frac{1}{e} \frac{P_{1}^{a}}{\frac{1}{2} P_{1}^{i}+P_{1}^{a}} \sum_{i=1}^{\min \left(t, t_{a}\right)} Q(t-i), E(t), P\right)
$$

Fig. 3 illustrates this property through simulation of young Coffea trees with stochastic development and arbitrary chosen, but realistic, functional parameters [8]. Whatever their topology is, the plants have similar biomass production profiles and partitioning dynamics.

\section{Discussion AND CONCLUSION}

Our results show that the biomass production is similar among young Coffea trees that have different topological developments. It has to be noted that these results were obtained under particular experimental conditions: the plants 
were young, the development time was relatively short and the plants grew without inter-individual competition for light. It seems unlikely that the same results could be obtained for adult Coffea trees, since topology will influence the growth, in particular through self-shading of leaves, position-dependent allocation of biomass, autonomy of branches, or ring growth effects (see for instance the results of [9] on Cotton plants). Our results nevertheless suggest that the biomass production is independent of the plant structure at a given time.

This result was analytically reproduced in the framework of a source-sink system with proportional allocation, under a list of hypotheses that were listed in part III. The potential explanations that are proposed are based on modelling hypotheses and theoretical derivations that now need to be tested through complete parameter estimation of a model. They are likely to be only approximately verified for real young Coffea trees but this analytical study can nevertheless help understanding the hidden mechanisms that underlie our experimental observations.

This theoretical analysis also gives insights in the effects of some assumptions that are classically done in a modelling context. We refer for instance to [10] for the GreenLab model [11]-[13]. In GreenLab, the $f$ function of (3) for biomass production is derived from the Beer-Lambert law, as inherited from Process-Based Models [14]. For any $f$ function that depends on the total blade area (and not on the areas of each blade), our theoretical analysis predicts that proportional source-sink models can generate biomass dynamics that do not depend on topological development, even though topology is explicitly described in the model. In that case, the model comes down to a process-based model at compartment scale.

Finally, our experimental results revealed that the partitioning of stem and leaf allocations changes with the species under similar growth conditions. A model-based approach will allow extracting the dynamics of biomass partitioning for these different species and should help identifying different allocation strategies that could be linked to the ecological conditions of species habitat.

\section{ACKNOWLEDGMENT}

We thank Marc Jaeger (AMAP) for the 3D production of the Gloups and Ligdraw software, Michael Guéroult (AMAP) who helped us for the measurements and Francis Richard (DIADE) for maintaining the plants in the IRD greenhouses.

\section{REFERENCES}

[1] P. Davis, R. Govaerts, D. Bridson, and P. Stoffelen, "An annoted taxonomic conspectus of genus coffea (rubiaceae)," Botanical Journal of the Linnean Society, vol. 152, pp. 465$512,2006$.
[2] C. Godin and Y. Caraglio, "A multiscale model of plant topological structures," Journal of Theoretical Biology, vol. 191, pp. 1-46, 1998.

[3] P. Borianne and G. Brunel, "Automated valuation of leaves area for large-scale analysis needing data coupling or petioles deletion," in International Symposium on Plant Growth Modeling, Simulation, Visualization and application, Y. Dumont and M.-Z. Kang, Eds. IEEE Computer Society, 2012, p. In Press.

[4] D. Barthélémy and Y. Caraglio, "Plant architecture: a dynamic, multilevel and comprehensive approach to plant form, structure and ontogeny," Annals of Botany, vol. 99, no. 3, pp. 375-407, 2007.

[5] X. Zhao, P. de Reffye, F. Xiong, B. Hu, and Z. Zhan, "Dualscale automaton model of virtual plant growth." Chinese Journal of Computers, vol. 24, no. 6, pp. 608-615, 2001.

[6] P. Prusinkiewicz and A. Lindenmayer, The Algorithmic Beauty of Plants. Springer-Verlag, New-York, 1990.

[7] X. Yin, J. Goudriaan, E. Lantinga, J. Vos, and H. Spiertz, "A flexible sigmoid function of determinate growth," Annals of Botany, vol. 91, pp. 361-373, 2003.

[8] J. Diao, P. De Reffye, X. Lei, H. Guo, and V. Letort, "Simulation of the topological development of young eucalyptus using a stochastic model and sampling measurement strategy," Computers and Electronics in Agriculture, vol. 80, pp. 105114, 2012.

[9] D. Li, V. Letort, Y. Guo, P. de Reffye, and Z. Zhan, "Modeling branching effects on source-sink relationships of the cotton plant," in Plant growth Modeling, simulation, visualization and their Applications., B.-G. Li, M. Jaeger, and Y. Guo, Eds. IEEE Computer Society, 2010, pp. 293-300.

[10] V. Letort, P.-H. Cournède, and P. De Reffye, "Impact of topology on plant functioning: a theoretical analysis based on the greenlab model equations," in Plant growth Modeling, simulation, visualization and their Applications., B.-G. Li, M. Jaeger, and Y. Guo, Eds. IEEE Computer Society, 2010, pp. 341-348.

[11] H. Yan, M. Kang, P. De Reffye, and M. Dingkuhn, “A dynamic, architectural plant model simulating resourcedependent growth," Annals of Botany, vol. 93, pp. 591-602, 2004.

[12] P. Cournède, M. Kang, A. Mathieu, J. Barczi, H. Yan, B. Hu, and P. de Reffye, "Structural factorization of plants to compute their functional and architectural growth," Simulation, vol. 82, no. 7, pp. 427-438, 2006.

[13] A. Mathieu, P.-H. Cournède, V. Letort, D. Barthelemy, and P. de Reffye, "A dynamic model of plant growth with interactions between development and functional mechanisms to study plant structural plasticity related to trophic competition," Annals of Botany, vol. 103, no. 3, pp. 1173-1186, 2009.

[14] L. Marcelis, E. Heuvelink, and J. Goudriaan, "Modelling of biomass production and yield of horticultural crops: a review," Scientia Horticulturae, vol. 74, pp. 83-111, 1998. 